\title{
Titanium Sapphire: A Decade of Diode-laser Pumping
}

\author{
Jamie C. E. Coyle', John-Mark Hopkins', Alexander A. Lagatsky's, and Alan J. Kemp \\ 1. Institute of Photonics, Dept. of Physics, SUPA, University of Strathclyde, Glasgow, G1 1RD, UK. \\ 2. Fraunhofer Center for Applied Photonics, Glasgow, G1 1RD, UK.
}

For many years, Ti:sapphire was the prototypical example of a solid-state laser material that could not be diode pumped. The rationale for this assessment follows from the laser properties of Ti:sapphire, which combine to demand high brightness pumping in the blue-green region (see fig. 1 [1]). The development of efficient Gallium Nitride (GaN) based laser diodes eroded this logic [2], and improvements in the spatial brightness of GaN diode lasers subsequently enabled the first demonstration of a directly diode-laser pumped Ti:sapphire laser in 2009 [3]. This presentation will outline the physics that makes diode-pumping difficult, and the developments that mean, it is, nonetheless, possible. Interestingly, diodepumping of CW and modelocked Ti:sapphire lasers was achieved not by a radical redesign of the laser, but by careful optimisation of existing approaches that enabled the rapidly improving brightness of GaN diode lasers to be exploited [3-5].

The performance of these early systems was modest. In part, this was because the performance of GaN diodes was still marginal for Ti:sapphire pumping. However, this early work hinted at a second issue that of pump induced loss for blue, rather than green pumping [3]. Rigorous subsequent work by Sawada et al. [6] and Moulton et al. [7] has begun to unpick the physics behind this effect. However, probably the most significant factor in the subsequent improvements in the performance and functionality of diodepumped Ti:sapphire lasers has been the emergence of higher power and longer wavelength GaN diode lasers. These diodes have been harnessed by a number of groups world-wide to enable ground-breaking demonstrations. Particular highlights include the demonstration of Kerr-lens modelocking [8], of a frequency comb [9], of a regenerative amplifier [10], of broad tuneability [11], and the announcement of a first commercial system [12]. This progress indicates a bright future for diode-pumped Ti:sapphire lasers.

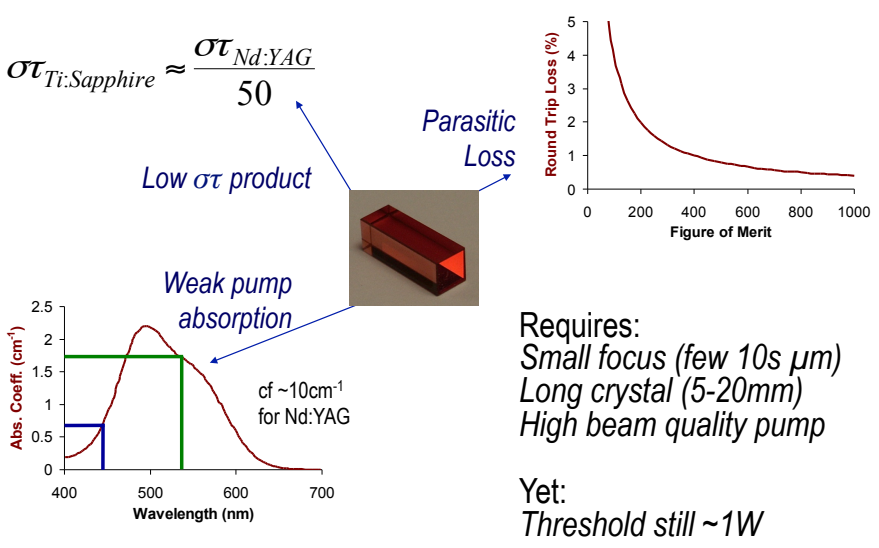

Fig. 1: Challenges for pumping Ti:sapphire (1 $\mathrm{cm}, 0.1 \mathrm{wt} \%$ crystal assumed)

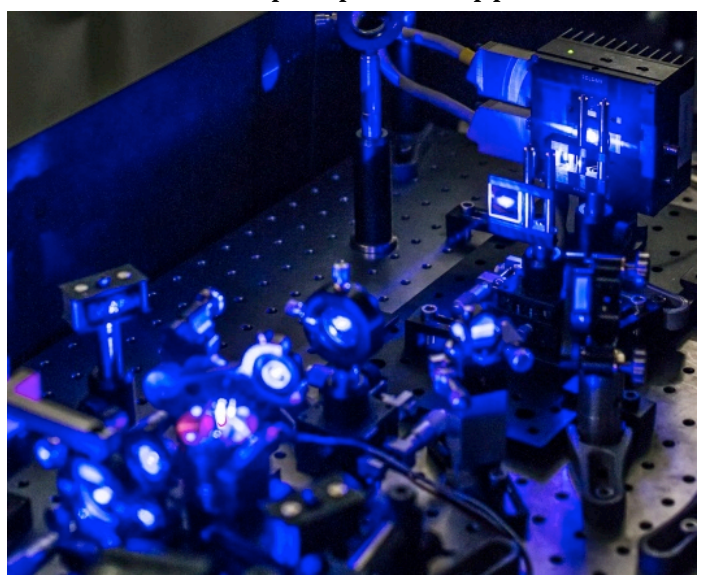

Fig. 2 : A diode-pumped Ti:sapphire laser

\section{References}

[1] P. F. Moulton, "Spectroscopic and Laser Characteristics of Ti: $\mathrm{Al}_{2} \mathrm{O}_{3}$," Journal of the Optical Society of America B-Optical Physics, vol. 3, pp. 125-133, 1986.

[2] S. Nakamura, "First III-V-nitride-based violet laser diodes," Journal of Crystal Growth, vol. 170, pp. 11-15, 1997.

[3] P. W. Roth, A. J. Maclean, D. Burns, and A. J. Kemp, "Directly diode-laser-pumped Ti:sapphire laser," Optics Letters, vol. 34, pp. 33343336, 2009.

[4] P. W. Roth, D. Burns, and A. J. Kemp, "Power scaling of a directly diode-laser-pumped Ti:sapphire laser," Optics Express, vol. 20, pp. 20629-20634, 2012.

[5] P. W. Roth, A. J. Maclean, D. Burns, and A. J. Kemp, "Direct diode-laser pumping of a mode-locked Ti:sapphire laser," Optics Letters, vol. 36, pp. 304-306, 2011.

[6] R. Sawada, H. Tanaka, N. Sugiyama, and F. Kannari, "Wavelength-multiplexed pumping with 478-and 520-nm indium gallium nitride laser diodes for Ti:sapphire laser," Applied Optics, vol. 56, pp. 1654-1661, 2017.

[7] P. F. Moulton, J. G. Cederberg, K. T. Stevens, G. Foundos, M. Koselja, and J. Preclikova, "Characterization of Absorption Bands in Ti:sapphire Crystals," in Laser Congress 2018 (ASSL), Boston, Massachusetts, 2018, AM4A.2.

[8] C. G. Durfee, T. Storz, J. Garlick, S. Hill, J. A. Squier, M. Kirchner, et al., "Direct diode-pumped Kerr-lens mode-locked Ti:sapphire laser," Optics Express, vol. 20, pp. 13677-13683, 2012.

[9] K. Gürel, V. J. Wittwer, S. Hakobyan, S. Schilt, and T. Südmeyer, "Carrier envelope offset frequency detection and stabilization of a diode-pumped mode-locked Ti:sapphire laser," Optics Letters, vol. 42, pp. 1035-1038, 2017.

[10] S. Backus, M. Kirchner, R. Lemons, D. Schmidt, C. Durfee, M. Murnane, et al., "Direct diode pumped Ti:sapphire ultrafast regenerative amplifier system," Optics Express, vol. 25, pp. 3666-3674, 2017.

[11] J. C. E. Coyle, A. J. Kemp, J.-M. Hopkins, and A. A. Lagatsky, "Ultrafast diode-pumped Ti:sapphire laser with broad tunability," Optics Express, vol. 26, pp. 6826-6832, 2018.

[12] J. Wallace, "KMLabs commercially introduces direct diode pumped Ti:sapphire ultrafast laser," Laser Focus World, vol. 53 , p. 11 , 2017. 


\section{0 word summary}

This presentation will review the challenges associated with diode-pumping of Ti:sapphire and the rapid recent progress made internationally in delivering diode-pumped Ti:sapphire lasers of increasing utility. 